\title{
Early onset and late onset preeclampsia-maternal and perinatal outcomes in a rural teritiary health center
}

\author{
Gomathy E., Lahari Akurati*, Kondareddy Radhika
}

Department of Obstetrics and Gynecology, Sri Devaraj Urs Medical College, Kolar, Karnataka, India

Received: 19 March 2018

Accepted: 21 April 2018

*Correspondence:

Dr. Lahari Akurati,

E-mail: lahari.199120@gmail.com

Copyright: (C) the author(s), publisher and licensee Medip Academy. This is an open-access article distributed under the terms of the Creative Commons Attribution Non-Commercial License, which permits unrestricted non-commercial use, distribution, and reproduction in any medium, provided the original work is properly cited.

\begin{abstract}
Background: Preeclampsia is main cause of morbidity and mortality both mother and fetus. Preeclampsia occurs in $10-17 \%$ of pregnancies. Preeclampsia was divided into early onset preeclampsia is occur at less <34 weeks of gestation age and late onset preeclampsia is occur at $>34$ weeks of gestation age. Early and late onset preeclampsia have different etiology and should be considered as different disease as there are difference in clinical manifestation, maternal and perinatal outcome, prognosis and complication.

Methods: An analytic observational study involving retrospective data done at RL Jalappa Hospital, Sri Devaraj Urs Medical College, Kolar. 217 women with singleton pregnancies with Pre eclampsia who were admitted and delivered in our hospital between June 2016 and May 2017 were recruited for this retrospective study.

Results: The results showed that the incidence of EOPE (27.6\%) was lower than LOPE (72.4\%). Diastolic blood pressure is significantly higher in EOPE compared to LOPE. Complications in perinatal outcomes such as low birth weight (<2500 gram) are more in EOPE $(98.3 \%)$ compared to LOPE $(45.2 \%)$ and asphyxia is more on EOPE $(11.7 \%)$ compared to LOPE (1.3\%). Stillbirth in EOPE (15\%) is more than LOPE group $(3.2 \%)$.

Conclusions: It is observed that EOPE incidence rate is lower than LOPE. Maternal and perinatal complications are greater in the EOPE group.
\end{abstract}

Keywords: Early and late onset preeclampsia, Fetal outcome, Maternal morbidity

\section{INTRODUCTION}

Pre eclampsia is a multisystem disorder occurring in pregnancy and puerperium which is characterised by development of hypertension of $140 / 90 \mathrm{mmHg}$ and above after $20^{\text {th }}$ week in a previously normotensive patient. ${ }^{1}$ It is a global problem and complicates approximately 10-17\% of pregnancies. The incidence of preeclampsia is 2 to $10 \%$ of all pregnancies in the world. According to WHO the incidence is 7 times greater in developing countries compared to developed countries. ${ }^{2}$ Currently there has been a change in the definition and understanding of Preeclampsia, known as Early Onset Preeclampsia (EOPE) and Late Onset Preeclampsia (LOPE).early onset where preeclampsia occurs at $<34$ weeks gestational age and late onset occurring at $>34$ weeks of gestation.Even though the presenting features overlap, there are differences in maternal and perinatal outcome, prognosis and complications. Early and late onset preeclampsia have different aetiologies and should be considered as different disease. ${ }^{3}$ Early onset preeclampsia is the most severe clinical variant of disease occurring $5-20 \%$ of all cases of preeclampsia and is associated with neonatal morbidity and mortality. Late onset preeclampsia occurring about $75-80 \%$ of all cases of preeclampsia; which are associated with maternal morbidity (metabolic syndrome, impaired glucose tolerance, obesity, dyslipidaemia, chronic hypertension), normal birth weight and normal placental volume. ${ }^{4}$ 


\section{METHODS}

217 women with singleton pregnancies with Pre eclampsia who were admitted and delivered in our hospital between June 2016 and May 2017 were recruited for this retrospective study.

Included patients $(n=217)$ were divided into two groups: Early onset preeclampsia (EOPE) group consisting of 60 patients diagnosed before 34 weeks of gestation, Late onset preeclampsia (LOPE) group consisting of 157 patients who were diagnosed at or after 34 weeks gestation.

Exclusion criteria include pregnant women with essential hypertension or hypertension <20 weeks gestation, pre existing renal disease, multiple pregnancies, liver disorder, and epilepsy. The two groups were matched according to age, education, gestational age, parity, clinical findings (systolic blood pressure, diastolic blood pressure). Maternal outcomes include duration of treatment, mode of delivery and foetal outcomes include birth Weight, apgar score at $5^{\text {th }}$ minute, intra uterine death (IUD), Still births were compared.

\section{Statistical analysis}

Data are expressed as $\mathrm{n}(\%)$ and mean with standard deviation.

The data were tested for normal distribution and Student's t test, One-way ANOVA or the Mann-Whitney $\mathrm{U}$ test was used for comparison of two groups where appropriate. Statistical Package for the Social Sciences (SPSS) 17.0. A p value $<0.05$ was regarded as significant.

\section{RESULTS}

A total of 217 patients at $>20$ weeks of gestation with pre eclampsia were taken in this study divided into EOPE and LOPE groups $(n=60$ and 157$)$ respectively.

Characteristics of preeclampsia were illustrated in Table $1 ; 148(68.2 \%)$ patients were in the age group 20 to 35 yrs. Education of patients were upto high school 128 $(59 \%)$. Majority of patients with pre eclampsia are multigravidas.

Based on the gestational age of PE, LOPE patients were 157 (72.4\%) more than EOPE 60 (27.4\%).

While the systolic blood pressure was on average $170.33 \pm 14.43$ and mean diastolic 107.06 \pm 9.557 .

Table 2 illustrates EOPE were found more in multigravida while LOPE were found more in primigravida which is statistically significant.
Table 1: Characteristics of patients with preeclampsia.

\begin{tabular}{|ll|}
\hline Variable & $\mathbf{N}=217$ \\
\hline Age (years) & $17(7.8 \%)$ \\
\hline$<20$ & $148(68.2 \%)$ \\
\hline $20-35$ & $52(24 \%)$ \\
\hline$>35$ & $57(26.3 \%)$ \\
\hline Education & $60(27.6 \%)$ \\
\hline Elementary & $74(34.1 \%)$ \\
\hline Middle school & $26(12 \%)$ \\
\hline High school & \\
\hline college & $89(41 \%)$ \\
\hline Parity & $128(59 \%)$ \\
\hline Primigravida & \\
\hline Multigravida & $60(27.6 \%)$ \\
\hline Gestational age (weeks) & $157(72.4 \%)$ \\
\hline$<34$ (EOPE) & \\
\hline$\geq 34$ (LOPE) & \\
\hline Blood pressure (mmHg) & $170.36 \pm 14.93$ \\
\hline Systolic & 170 \\
\hline Mean & $120-230$ \\
\hline Median & $107.08 \pm 9.804$ \\
\hline Range & 110 \\
\hline Diastolic & $90-160$ \\
\hline Mean & \\
\hline Median & \\
\hline Range & \\
\hline
\end{tabular}

Table 2: Characteristics of patients EOPE and LOPE.

\begin{tabular}{|c|c|c|c|}
\hline Variable & $\begin{array}{l}\text { EOPE } \\
(n=60)\end{array}$ & $\begin{array}{l}\text { LOPE } \\
(n=157)\end{array}$ & P value \\
\hline \multicolumn{4}{|l|}{ Age (years) } \\
\hline$<20$ & $5(8.3 \%)$ & $24(15.3 \%)$ & \multirow{3}{*}{0.0473} \\
\hline $20-35$ & $42(70 \%)$ & $95(60.5 \%)$ & \\
\hline$>35$ & $13(21.7 \%)$ & $38(24.2 \%)$ & \\
\hline \multicolumn{4}{|l|}{ Education } \\
\hline Elementary & $14(23.4 \%)$ & $38(24.2 \%)$ & \multirow{4}{*}{1.000} \\
\hline $\begin{array}{l}\text { Middle } \\
\text { school }\end{array}$ & $16(26.7 \%)$ & $47(30 \%)$ & \\
\hline High school & $25(41.6 \%)$ & $60(38.2 \%)$ & \\
\hline College & $5(8.3 \%)$ & $12(7.6 \%)$ & \\
\hline \multicolumn{4}{|l|}{ Parity } \\
\hline Primigravida & $32(53.3 \%)$ & $92(58.6 \%)$ & \multirow{2}{*}{$0.017^{*}$} \\
\hline multigravida & $28(46.7 \%)$ & $65(41.4 \%)$ & \\
\hline \multicolumn{4}{|c|}{ Blood pressure :Systolic } \\
\hline Mean & $173.16 \pm 17.9$ & $169.26 \pm 12.75$ & \multirow{3}{*}{0.073} \\
\hline Median & 170 & 170 & \\
\hline Range & $140-250$ & $120-230$ & \\
\hline \multicolumn{4}{|l|}{ Diastolic } \\
\hline Mean & $109.71 \pm 10.76$ & $106.05 \pm 8.71$ & \multirow{3}{*}{$0.002 *$} \\
\hline Median & 110 & 110 & \\
\hline Range & $100-150$ & $60-160$ & \\
\hline
\end{tabular}


Table 3: Maternal and perinatal outcomes of patients EOPE and LOPE.

\begin{tabular}{|c|c|c|c|}
\hline Variable & EOPE $(n=60)$ & LOPE $(n=157)$ & P value \\
\hline \multicolumn{4}{|l|}{ Mode of delivery } \\
\hline Caesarean section & $32(53.3 \%)$ & $92(58.6 \%)$ & \multirow{2}{*}{0.366} \\
\hline Vaginal delivery & $28(46.7 \%)$ & $65(41.4 \%)$ & \\
\hline \multicolumn{4}{|l|}{ Vaginal delivery } \\
\hline Spontaneous & $25(89.3 \%)$ & $15(23.1 \%)$ & \multirow{4}{*}{$0.0001 *$} \\
\hline Forceps & $2(7.1 \%)$ & $47(72.3 \%)$ & \\
\hline Vacuum & $0(0)$ & $2(3.1 \%)$ & \\
\hline Episiotomy & $1(3.6 \%)$ & $1(1.3 \%)$ & \\
\hline \multicolumn{4}{|c|}{ Length of hospital stay(days) } \\
\hline Mean & 5.59 & 5.32 & \multirow{3}{*}{$0.0001 *$} \\
\hline Median & 4 & 4 & \\
\hline Range (min-max) & $1-92$ & $1-35$ & \\
\hline \multicolumn{4}{|l|}{ Birth weight } \\
\hline$<2000 \mathrm{gm}$ & $55(91.6 \%)$ & $24(15.2 \%)$ & \multirow{3}{*}{$0.0001 *$} \\
\hline 2000-2499gm & $4(6.7 \%)$ & $47(30.0 \%)$ & \\
\hline$>2500 \mathrm{gm}$ & $1(1.7 \%)$ & $86(54.8 \%)$ & \\
\hline \multicolumn{4}{|l|}{ Apgar score (5min) } \\
\hline Asphyxia & $7(11.7 \%)$ & $2(1.3 \%)$ & \multirow{3}{*}{$0.0001 *$} \\
\hline Not asphyxia & $44(73.3 \%)$ & $150(95.5 \%)$ & \\
\hline Stillborn & $9(15 \%)$ & $5(3.2 \%)$ & \\
\hline
\end{tabular}

Blood pressure increases in both EOPE and LOPE but increase of diastolic pressure is more on EOPE than LOPE which is statistically significant.

Table 3 illustrates the comparison of outcomes in patients with EOPE and LOPE. Most deliveries are performed by caesarean section; $53 \%$ in EOPE and $58.6 \%$ in LOPE but not statistically significant. Spontaneous deliveries are more in EOPE group than in LOPE which is statistically significant. Duration of hospital stay is more in EOPE group than in LOPE which is significant. EOPE has more babies born weighing $<2500 \mathrm{~g}(91.6 \%)$ where as in LOPE it weighs $\geq 2500$ grams $(54.8 \%)$. Babies who are born in EOPE groups had asphyxia (11.7\%) more than babies in LOPE group (1.3\%).

\section{DISCUSSION}

Approaching as an early onset and late onset preeclampsia gives us better idea about understanding of the complex etiopathogenesis of this medical enigma.

The distinction between early onset and late onset PE is a relatively modern concept and is becoming widely accepted as a better indicator of disease significance ${ }^{5}$.

In our study the incidence of pre-eclampsia more in late onset (LOPE) than early onset preeclampsia (EOPE) group $(72.4 \%$ vs $27.6 \%)$. Clinical characteristics like systolic blood pressure (SBP), diastolic blood pressure (DBP) were significantly higher in early onset (EOPE) group suggesting increased maternal total vascular resistance which strengthens abnormal placentation as the probable cause for early onset subtype.

In our study gestational age at birth had a major impact on perinatal morbidity and mortality. Early onset group had early termination of pregnancy due to uncontrolled blood pressure, derangement of laboratory parameters and clinical manifestations. Perinatal mortality and still birth rates were higher in early onset preeclampsia (EOPE) than in late onset preeclampsia (LOPE).

Early onset preeclampsia (EOPE) is associated with increased risk of multi organ involvement including hepatic, hematologic, arterial, renal and adverse maternal and perinatal outcomes as compared with late onset preeclampsia (LOPE).

There are limited number of studies and reviews that have compared characteristics of early onset and late onset pre-eclampsia.

In a study conducted by Aziz, Mose, Indonesia shows maternal and perinatal morbidity and mortality is higher in EOPE group. ${ }^{6}$

Valensis et al. reported that patients who were diagnosed with EO-PE had higher total vascular resistance, while late-onset patients had low vascular resistance. ${ }^{7}$

In a study conducted by sreedevi atluri and nandish in mysore shows EOPE is more severe clinical entity than LOPE with high risk for life threatening maternal complications and fetal mortality. ${ }^{8}$ 
The distinction between EO- and LO-PE is a relatively modern concept and is becoming widely accepted as a better indicator of disease significance than the classic "mild" vs "severe" terminology. ${ }^{9}$ It was widely demonstrated that gestational age at birth had a major impact on perinatal outcome. ${ }^{10}$ Perinatal mortality and morbidity were demonstrated to be higher in women with EO-PE. ${ }^{11-13}$ The results of the present study supported this observation.

\section{CONCLUSION}

Preeclampsia is a major complication in pregnancy with significant short term and long term consequences for both mother and foetus. currently, no therapies are available to slow or reverse the disease. A recent review by Sibai supported expectant management in selected cases of severe PE presenting before 34 weeks, good perinatal outcomes were reported. The provision of MgSO4 40\% as a brain protector and corticosteroids to infant lung maturation can reduce complications of perinatal outcomes. CLASP (collaborative low-dose asprin study in pregnancy) trail showed usage of low dose asprin prophylactically in patients liable to early onset preeclampsia has better perinatal outcome.

\section{Funding: No funding sources}

Conflict of interest: None declared

Ethical approval: The study was approved by the Institutional Ethics Committee

\section{REFERENCES}

1. Sibai BM. Hypertension in pregnancy. Clinical Obstet Gynecol. 1999: 421-436.

2. Kooffreh ME, Ekott M, Ekpoudom DO. The Prevalence of Preeclampsia Among Pregnant Women in The University of Calabar Teaching Hospital, Calabar. Saudi J Health Sci. 2014;3(3):1336.

3. Hellaman LM, Pritchard J. Williams obstetrics. 14 ed. World Health Organization; Maternal mortality. Fact sheet $\mathrm{N}^{\circ} 348$, May 2014. Available from http://www.who.int/mediacentre/factsheets/fs348/en. Accessed on 24 March 2018.

4. Madazli R, Yuksel MA, Imamoglu M, Tuten A, Oncul M, et al. (2014) Comparison of clinical and perinatal outcomes in early- and late-onset preeclampsia. Arch Gynecol Obstet. 2014;290(1):537.

5. Urner JA. Diagnosis and management of preeclampsia:an update. Int $\mathbf{J}$ Women Health. 2010;2:327-37.

6. Aziz A, Mose JC. The Differences of Characteristic, Management, Maternal and Perinatal outcomes among Early and Late Onset Preeclampsia. Open Access Library J. 2016;3:e2750.

7. Valensise H, Vasapollo B, Gadgliardi G, Novelli GP. Early and late preeclampsia: two different maternal hemodynamic states in the latent phase of the disease. Hypertension. 2008;52:873-80.

8. Atluri S, Manoli NS. Comparative study of maternal and perinatal outcome in early onset and late onset preeclampsia. J. Evid. Based Med. Healthc. 2017;4(9):499-504.

9. Turner JA. Diagnosis and management of preeclampsia:an update. Int $\mathbf{J}$ Women Health. 2010;2:327-37.

10. Steegers EA, von Dadelszen P, Duvekot JJ, Pijnenborg R. Preeclampsia. Lancet. 2010;376:63144.

11. Duley L. The global impact of pre-eclampsia and eclampsia. Semin Perinatol. 2009;33:130-7.

12. Sibai BM. Management of Late Pretern and EarlyTerm Pregnancies Complicated by Mild Gestational Hypertension/Pre-Eclampsia. Seminars in Perinatol. 2011;35:292-6.

13. Sibai BM. What to Expectant Management in Severe Preeclampsia at <34 Weeks Gestation: Pregnancy Outcomes in Developed vs Developing Countries. Am J Obstet Gynecol. 2013;209:400-1.

Cite this article as: Gomathy E, Lahari A, Kondareddy R. Early onset and late onset preeclampsia-maternal and perinatal outcomes in a rural teritiary health center. Int J Reprod Contracept Obstet Gynecol 2018;7:2266-9. 